\title{
Bioassay for Salmon Prolactin Using Hypophysectomized
} Fundulus heteroclitus

\author{
E. Gordon Grau, ${ }^{1}$ Patrick Prunet, ${ }^{2}$, Thomas Gross, Richard S. Nishioka, and \\ HOWARD A. BERN \\ Department of Zoology and Cancer Research Laboratory, University of California, \\ Berkeley, California 94720
}

Accepted January 6, 1983

\begin{abstract}
A bioassay for salmon prolactin (PRL) is described. This assay which is based on the sodium-retaining action of PRL in the hypophysectomized killifish, Fundulus heteroclitus, has proved to be rapid, sensitive ( $250 \mathrm{pg}$ PRL per gram of fish), and specific. The procedure has been used to characterize the biological activity of a highly purified PRL from the pituitaries of the chinook salmon, Oncorhynchus tschawytscha, and a similar PRL isolated (by acid buffer polyacrylamide disc gel electrophoresis) from pituitaries of coho salmon ( $O$. kisutch) (MW ca. 22,000; isoelectric point >9).
\end{abstract}

Prolactin (PRL) is essential in teleost fish for maintaining salt and water balance in fresh-water (for review see Clarke and Bern, 1980; Loretz and Bern, 1982). Indeed, because of a fall in plasma electrolytes (Burden, 1956; Pickford and Phillips, 1959) some euryhaline species cannot survive in fresh-water if deprived of this hormone. Thus, one important result of PRL action in many teleosts is its ability to maintain and even increase plasma electrolyte concentrations, including $\mathrm{Na}^{+}$(for example see Pickford et al., 1966; Ensor and Ball, 1968, 1972; Bern, 1975). The ability to enhance plasma sodium levels in teleosts appears to be specific to PRL (including human growth hormone $(\mathrm{hGH})$ ), and no other hormone has as yet demonstrated similar activity (Pickford et al., 1965; Ball and Ensor, 1967; Lahlou and Giordan, 1970; Clarke, 1973). For this reason the "sodium-retaining"' activity of PRL in teleosts has

\footnotetext{
1 To whom reprint requests should be sent at Department of Zoology, University of Hawaii at Manoa, Honolulu, Hawaii 96822.

2 Present address: Laboratoire de Physiologie des Poissons, INRA, Campus de Rennes-Beaulieu, 35042 Rennes, France.
}

been used repeatedly as a basis for the development of PRL bioassays (for examples, see Ensor and Ball, 1968; Clarke, 1973).

Recently there has been wide interest not only in defining the actions of PRL but also in elucidating its pattern of secretion during the period of parr-smolt transformation (smoltification) in migratory salmon and trout. This interest derives from two sorts of observations. First, smoltification, a developmental process associated with the seaward migration of anadromous salmonids, appears to be in many aspects analogous to amphibian metamorphosis, in which PRL may oppose metamorphic changes while stimulating tadpole growth (Frye et al., 1972). Second, during smoltification young salmonids leave fresh-water for marine salinities, where osmotic problems are opposite those whose solution is favored by PRL. Accordingly, a significant change in the pattern of PRL secretion might be expected at this time. Several laboratories in Japan, France, and North America have undertaken programs to produce quantities of salmon PRL for experimental use in the hopes of developing a radioimmunoassay for use in quantifying blood and pituitary concentrations of this 
critically important osmoregulatory and developmental hormone.

Until now, however, a suitable teleost bioassay for salmon PRL, essential for proceeding with hormone purification, has not been reported. Salmonid hypophysectomy is difficult to perform, making the logical assay animal virtually unavailable. In addition, the response of intact salmon to PRL is inconsistent (W. C. Clarke, personal communication). Herein, we present a rapid, sensitive, specific, and reliable bioassay for salmon PRL based on the sodium-retaining activity of this hormone in the hypophysectomized euryhaline killifish, Fundulus heteroclitus, the teleost in which the osmoregulatory action of PRL was first demonstrated (Pickford and Phillips, 1959).

\section{MATERIALS AND METHODS}

Bioassay animals. Adult $F$. heteroclitus of both sexes weighing from 6 to $12 \mathrm{~g}$, but generally between 7 and $9 \mathrm{~g}$, were used throughout these studies. These fish were caught in tidal creeks near Lewes, Delaware, and shipped by air to Berkeley, California, where they were held outdoors under ambient conditions in 200gal concrete aquaria in fresh-water and in artificial seawater (changed weekly). They were fed a mixed diet of adult Artemia and trout chow.

Hypophysectomy was performed according to a method described by Grau and Stetson (1977) under 2-phenoxyethanol anesthesia (Sigma, St. Louis, Mo.) (2.5 inl per 8 liter $\mathrm{H}_{2} \mathrm{O}$, Sehdev et al., 1963). Following hypophysectomy the fish were held for 5 days to 2 weeks (generally 1 week) in 25 -liter plastic aquaria (10 per tank) at $20 \pm 2^{\circ}$ in $26^{\circ} / 00$ artificial seawater (Marine Environment; Import Assoc. Inc., San Francisco, Calif.) under photoperiod conditions of $14 \mathrm{hr}$ of light and $10 \mathrm{hr}$ of dark.

Bioassay procedure. The fish were weighed and injected once intraperitoneally through the hypaxial musculature between 10 and $11 \mathrm{AM}$. The purified hormones were delivered in a $0.9 \%$ saline vehicle in a volume of $10 \mu \mathrm{l} / \mathrm{g}$ of fish. After the single hormone or control injection the fish were transferred to fresh water $(20 \pm 2$ ) aquaria (25 liter) and held for 24 to 30 hr until sacrifice.

At termination blood was collected in capillary tubes treated with ammonium heparin from the hemal arch at the caudal peduncle which was exposed by severing the tail. Plasma sodium levels were determined by using a Perkin-Elmer 290 atomic absorption spectrophotometer.
Hormones and pituitary materials. Ovine prolactiti (oPRL; NIH P-S10) and ovine growth hormone (OGH; $\mathrm{NIH} \mathrm{GH-S11)} \mathrm{were} \mathrm{gifts} \mathrm{of} \mathrm{National} \mathrm{Hormone} \mathrm{and}$ Pituitary Program, Baltimore, Maryland; bovine growth hormone $(\mathrm{bGH})$ was kindly donated by Professor C. H. Li.

Coho salmon rostral pars distalis (RPD), containing PRL cells, and proximal pars distalis (PPD), containing GH cells, were incubated at $14^{\circ}$ in $300 \mu 1$ of sodium bicarbonate-Ringer ( $320 \mathrm{mOsm})$ containing Eagle's MEM (Gibco), L-glutamine, and glucose (for composition see Aida et al., (1980)). The pittitary fragments were then homogenized in their respective culture media and immediately injected as above at a dose equivalent to one RPD or one PPD per fish.

Statistics. The statistical significance of the plasma sodium responses to $O P R L$ and chinook salmon putative PRL was tested using a log dose regression analysis of variance method (Steel and Torrie, 1960), The index of precision $\lambda$ (Bliss, 1967), was also caleulated. Other differences were tested for significance using analysis of variance and Duncan's multiple range test (Steel and lorrie, 1960).

\section{RESULTS}

The specific association of the sodiumretaining action with PRLs and primate GHs is well characterized in teleosts generally and in Fundulus in particular (Burden, 1956; Pickford and Phillips, 1959; Pickford et al., 1965, 1966; Ball and Evisor, 1967; Clarke, 1973). Whereas our findings are, with one exception, largely confirmatory, they demonstrate the dose-related nature of the sodium-retaining effects of PRL in Fundulus and extend the action to purified salmon hormone.

\section{Experiment 1}

Table 1 shows the response of hypophysectomized Fundulus in our assay system to a homogenate of the PRL cell-containing RPD (prepared as describcd above) and to a standard dose of oPRL. On the basis of the large and significant response in this preliminary study we began further testing to determine the specificity, sensitivity, and dose dependency of this assay system.

\section{Experiment 2}

In order to determine whether sodiumretaining activity is restricted in salmon to 
TABLE 1

EfFect of Ovine Prolactin (oPRL) AND HoMOgEnate of CoHo SaLmon (Oncorhynchus kisutch) Rostral Pars Distalis (RPD) on Plasma SODIUM CONCENTRATION IN HYPOPHYSECTOMIZED Fundulus heteroclitus

\begin{tabular}{lcc}
\hline \multicolumn{1}{c}{ Treatment } & $N$ & $\begin{array}{c}\text { Plasima } \mathrm{Na}^{+} \text {in mM } \\
\text { (mean } \pm \mathrm{SE})\end{array}$ \\
\hline Saline & 14 & $150.7 \pm 2.8$ \\
oPRL $(30 \mu \mathrm{g} / \mathrm{g})$ & 15 & $179.7 \pm 2.7$ \\
Salmon RPD & 15 & $171.9 \pm 2.6$ \\
\hline
\end{tabular}

the PRL cells of the RPD, as it is in the pituitary of other teleost species, homogenates of this tissue and tissue from PPD, as control, were prepared and administered to two separate groups as described above. Two additional groups were given injections of oPRL $(30 \mu \mathrm{g} / \mathrm{g})$ and $\mathrm{oGH}(30 \mu \mathrm{g} / \mathrm{g})$, respectively. The RPD homogenate, oPRL, and, surprisingly, oGH, all produced a significant elevation in plasma sodium compared with control values (Fig. 1). In contrast, the PPD homogenate failed to elicit a statistically significant response, although mean plasma sodium appeared to be slightly elevated. It is possible that this weak, though insignificant, response was due to imperfect separation of PPD and RPD tissue.

\section{Experiment 3}

Inasmuch as a significant sodium-retention response to nonprimate mammalian growth hormone in a teleost was unprecedented to our knowledge (Experiment 2), our finding posed both an interesting physiological question and a troublesome problem as to the suitability of the hypophysectomized Fundulus as a PRL bioassay animal.

We further investigated this question of specificity by treating hypophysectomized Fundulus using graded doses of oGH and highly purified bGH (Fig. 2). In neither case did these treatments elicit any changes in plasma $\mathrm{Na}^{+}$when administered to hypophysectomized Fundulus.

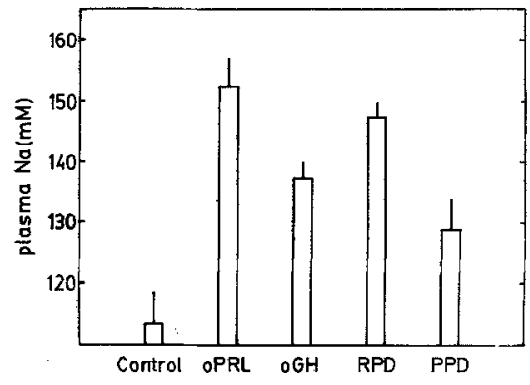

FIG. 1. Response (mean $\pm \mathrm{SE}$ ) of hypophysectomized $F$. heteroclitus to ovine prolactin (oPRL), ovine growth hormone (oGH), rostral pars distalis (RPD), and proximal pars distalis (PPD) from pituitaries of coho salmon, $O$. kisutch $(N=9-11)$.

\section{Experiment 4}

Our preliminary disc gel electrophoresis studies had shown no protein band unique to coho RPD in gels run in a basic buffer system. In an acid buffer system, however, a distinct and unique band was seen. When the RPD band was eluted and run in an isoelectrofocusing system, it had an isoelectric point greater than 9. In sodium dodecyl sulfate electrophoresis, the RPD band had a molecular weight of approximately 22,000 .

To determine whether this unique RPD band had sodium-retaining activity, hypophysectomized $F$. heteroclitus were in-

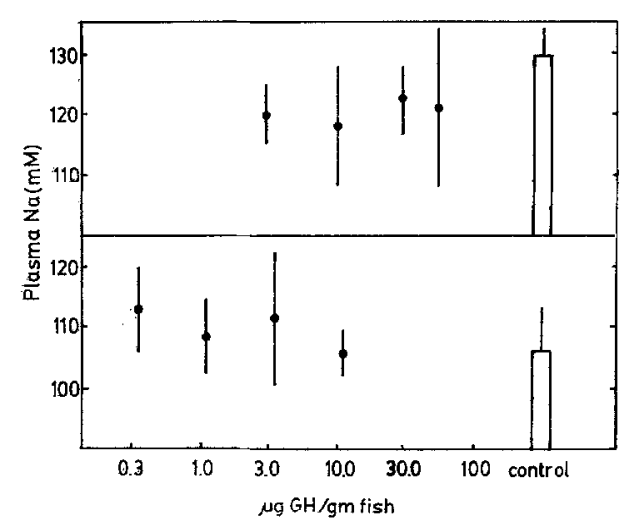

FIG. 2. Failure of plasma sodium in $F$. heteroclitus to respond to graded doses of oGH (NIH-GH-S11; top) and bGH (C. H. Li; bottom) (mean $\pm \mathrm{SE} ; N=$ $7-10$ except in one group where $N=5$ ). 
jected with material electrophoresed from each of three RPDs which had been eluted overnight by diffusion from the gel into $0.9 \% \mathrm{NaCl}$. A nonstaining section of the gel was eluted as a control. The putative coho PRL band elicited a small but significant $(P$ $<0.01$ ) elevation in plasma sodium (Fig. 3 ).

\section{Experiment 5}

Figure 4 shows a log dose-response curve generated to graded doses of oPRL in hypophysectomized Fundulus. Figure 5 shows the log dose-response pattern to the PRL fraction purified from the pituitary of chinook salmon (see Prunet and Houdebine, 1983). Both ovine and salmon preparations were assayed within the same period ( 2 weeks) using fish sacrificed $30 \mathrm{hr}$ after hormone injection. We have found that lengthening the time between injection and sacrifice (E. G. Grau and P. Prunet, unpublished results) results in lower plasma $\mathrm{Na}^{+}$levels in control animals; this would seem to allow more latitude for a significant response to be recorded at lower hormone doses.

Several points can be noted about the results of this study. First, whereas both preparations elicited significant (oPRL: $P$ $<0.008$; chinook salmon PRL: $P<0.0001)$

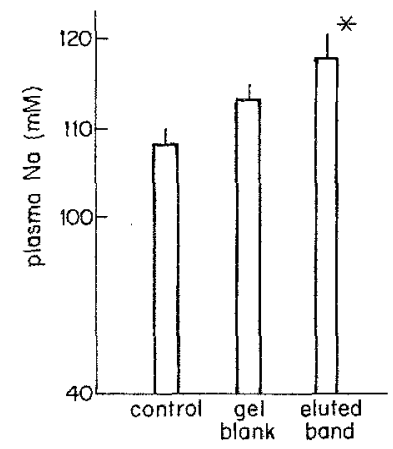

FIG. 3. Effect of eluted (prolactin) band on plasma sodium in hypophysectomized $F$. heteroclitus (mean $\pm S E: N=10-16 ; *$ denotes significant difference, $P<0.01$, from control).

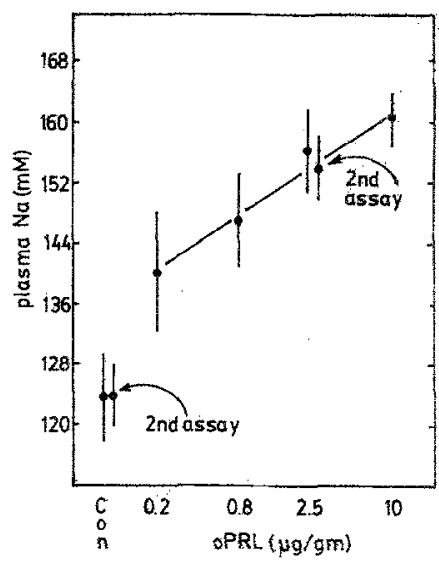

Frg. 4. Log dose-response curve for plasma sodium in hypophysectomized $F$, heteroclitus in response to ovine prolactin (oPRL; NIH-P S10) $(N=8-10$ per treatment: $F=7.85 ; P<0.008 ; \lambda=2.98)$.

and linear dose-response patterns, the minimally effective dose of the chinook salmon preparation was more than two orders of magnitude lower than that of the ovine preparation. Moreover, the slope of

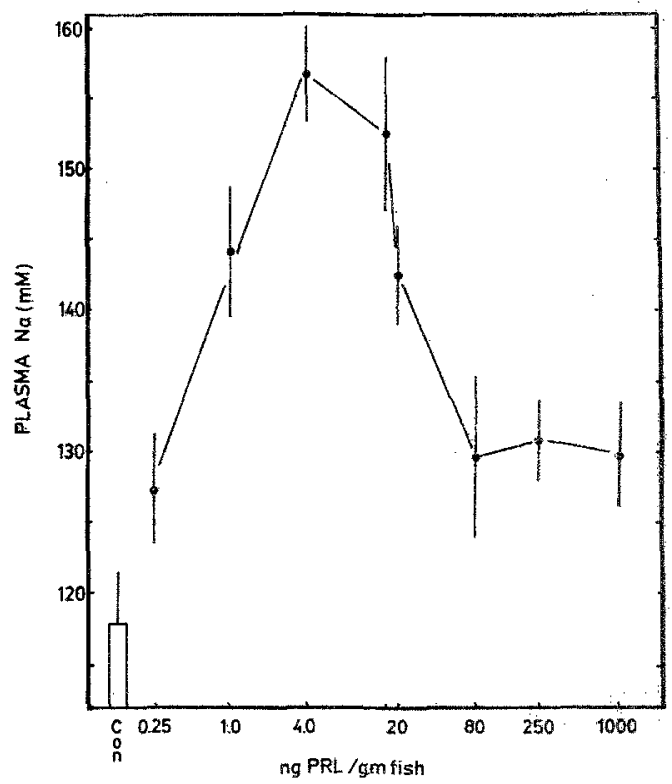

Fig. 5. Log dose-response cirve for plasma sodium in hypophysectomized $F$. heteroclitus in response to chinook salmon prolactin (Prunet and Houdebine, 1983) $(N=8-10$ per treatment: $F=24.9 ; p<0.001$ $\lambda=1.17$ ). 
the linear portion of the dose-response pattern was nearly eight times steeper than that generated for oPRL.

Second, amounts of the salmon preparation above the maximally effective dose were less effective in maintaining plasma sodium levels, although in all cases these levels were significantly higher than those recorded for controls. We have observed a similar depression of the response previously when high doses of oPRL were administered to Fundulus sacrificed $24 \mathrm{hr}$ postinjection.

\section{DISCUSSION}

Initially, several bioassay systems were screened for their suitability of detecting salmon PRL. These were the tilapia sodium-retaining assay of Clarke (1973), a sodium-retaining assay employing the mudsucker, Gillichthys mirabilis (C. Loretz and E. G. Grau, unpublished results), an assay using hypophysectomized tilapia similar to that described here for Fundulus (T. Gross, unpublished results), and the "xanthophore pigment dispersion" assay of Sage and Bern (1972). In each, the coho salmon RPD homogenate lacked consistent activity, although oPRL was generally effective.

Among the teleost bioassays for PRL, one of the most sensitive and reliable and best characterized is a sodium-retaining assay using the hypophysectomized molly, Poecilia latipinna (Ensor and Ball, 1968). Idler et al. (1978) employed this assay with some success to characterize purified chum salmon (Oncorhynchus keta) pituitary fractions, although they were unable to generate a dose-related reponse pattern to their salmon preparations.

$F$. heteroclitus, a species related to Poecilia, was available to us and appeared to be an excellent candidate for the bioassay of PRL isolated from the salmon pituitary. As in previous studies (for review, see Clarke and Bern (1980)) oPRL proved effective in maintaining plasma sodium in hypophysectomized Fundulus at levels well above those found in controls. In these studies, the sodium-retaining response was found to be dose-related in Fundulus, pointing to the potential usefulness of this species in the biological characterization of prolactins of teleost origin.

The unique association of teleost sodiumretaining activity with lactogenic mammalian hormones (PRLs and primate GHs) is perhaps best characterized for Fundulus (for examples, see Pickford and Phillips, 1959; Pickford et al., 1965, 1966). Together with the evidence accumulated for other teleosts (for discussion see Clarke, 1973), the unique occurrence of elevated plasma sodium levels in oGH-treated animals in Experiment 2 was surprising, and is as yet not entirely explained. It is worth noting, however, that the oGH preparation used in our studies has been found to contain considerable PRL activity ( 0.3 to $2.0 \%$; mean $\simeq 1 \%$ ) in the pigeon crop sac bioassay (Nicoll, personal communication). On this basis, the dose of oGH given in Experiment 2 would provide approximately $0.3 \mu \mathrm{g} / \mathrm{g}$ oPRL, a dose slightly higher than that which produced a comparable and highly significant elevation in plasma sodium in Experiment 5 (see Fig. 4). Thus, the sodium-retaining effect of oGH in Experiment 2 may possibly be explained by its contamination with oPRL. This explanation, however, is made tenous by the complete absence of response to several doses of the same oGH preparation subsequently (see Experiment 3), which raises the issue of a possible seasonal change in sensitivity of Fundulus.

Contamination or not, the conclusion of previous investigations that among mammalian hormones teleost sodium-retaining activity is restricted to those possessing lactogenic activity would appear to be confirmed here inasmuch as highly purified bGH (C. H. Li) was also without effect in the present investigations.

With respect to salmon, homogenates of RPDs and incubation medium from pitui- 
taries of coho salmon, unlike their PPD zounterparts, possess considerable and significant sodium-retaining activity. These findings are compatible with the accepted notion that among teleosts generally sodium-retaining activity is restricted to cells of the RPD which secrete a hormone broadly similar to mammalian PRLs (including primate $\mathrm{GHs}$ ).

For coho salmon this sodium-retaining activity of the RPD appears to be restricted to a protein with a molecular weight of approximately 22,000 and an isoelectric point above 9 , which runs with a unique $R_{f}$ in acid polyacrylamide disc gel electrophoresis. With respect to these criteria, the coho material (prolactin) is not distinguishable from chinook salmon PRL characterized by Prunet and Houdebine (1983).

Chinook salmon PRL is clearly more potent than oPRL in sodium-retaining activity (Figs. 4 and 5). The minimally effective dose of salmon material ( $250 \mathrm{pg} / \mathrm{g}$ fish) was more than two orders of magnitude lower than that for oPRL (NIH-P-S1;0). Even more impressive is the slope of the linear portion of the log dose-response curve for salmon PRL which was nearly 8 times steeper than that generated by oPRL. Using Clarke's (1973) tilapia sodium-retaining assay, Farmer et al. (1977) found, similarly, that tilapia PRL was approximately 160 times more active than oPRL. Taken together, these observations may point to a fairly high, though not absolute, degree of phylogenetic specificity in the biochemical requirements for PRL (sodium-retaining) activity among teleosts generally. Teleost fish bioassays may thus provide a useful tool for the study of molecular evolution by aiding in the identification of those structural features shared by hormones possessing sodium-retaining activity.

The high sensitivity of hypophysectomized Fundulus for chinook salmon PRL (25 pglg fish) is also particularly advanta- geous in the practical sense of conserving valuable hormone, since an $8 \mathrm{~g}$ fish requires only 2 ng of hormone to show a positive response.

The parabolic shape of the log dose-response curve for chinook salmon PRLs (Fig. 5) is fairly typical for hormone bioassays generally (e.g., Licht and Crews, 1976; Muller, 1977; Muller and Licht, 1980; BonaGallo and Licht, 1981). It is particularly interesting that whereas high doses (above 4 $\mathrm{ng} / \mathrm{g}$ fish) were somewhat less effective in promoting sodium retention, they did in every case elicit a positive and significant elevation compared with controls. Whether the higher doses are physiological cannot be answered here, but it is worth noting that the character, if not the degree of the response, is identical within the range of doses we examined. It is also true, however, that a comparison of hormone potencies requires the full and detailed elucidation of dose-response relationships.

Along this line, Idler et al (1978) demonstrated that certain purified fractions from chum salmon pituitaries could maintain significantly elevated plasma sodium levels in hypophysectomized Poecilia. They were, however, unable to show that the effect was dose-dependent, but the range of doses used was considerably higher than that used in our studies. If Poecilia and Fundulus, which are closely related, are comparably responsive to salmon PRLs, it is possible that the lowest dases used by Idler and co-workers (1978) (25 and $50 \mathrm{mg} / \mathrm{fish}$ ) were above the dose-dependent range for the sodium-retaining effect of salmon PRLs in the Poecilia assay system. Their preparations may therefore contain far more activity than previously suspected.

We have not as yet extensively tested other salmon PRLs in the hypophysectomized Fundulus assay. In conjunction with Dr. T. Hirano of the University of Tokyo, who is presently undertaking definitive 
testing, we have carried out preliminary studies on a chum salmon PRL kindly provided by Dr. H. Kawauchi of Kitasato University. Without implying any characterization of its relative potency, we have found that this chum salmon PRL preparation acted similarly to chinook salmon PRL at the few doses tested. Together with the activity of coho salmon RPD homogenates, these findings suggest that this Fundulus assay system may have broad applicability to the biological characterization of PRLs from various salmonids, and perhaps from other teleosts as well.

In sum, the method described herein provides a rapid and simple assay for salmon PRL, which meets the requirements of specificity, sensitivity and dose-dependency.

Note added in proof. A detailed study of chum salmon prolactin has recently been published (H. Kawauchi, K.-I. Abe, A. Takahashi, T. Hirano, S. Hasegawa, N. Naito, and Y. Nakai (1983). Gen. Comp. Endocrinol. 49, 446-458).

\section{ACKNOWLEDGMENTS}

We thank N. Harold Richman for statistical advice, Susan Steiny, Richard Lin, Rodolfo Rivas, and John Wood for technical assistance, and Christopher Brown for obtaining the Fundulus heteroclitus used in these studies. We also thank the California Department of Fish and Game for their essential help in providing the salmon. This work is a result of research sponsored in part by NOAA, National Sea Grant College Program, Department of Commerce, under Grant NOAAO4-8189, through the California Sea Grant College Program, and in part by the California State Resources Agency, project number R/F-78. The U.S. Government is authorized to produce and distribute reprints for governmental purposes. Aided also by NSF Grant PCM 81-10111 and NIH Fellowship 5 F32 HD057602 (E.G.G.).

\section{REFERENCES}

Aida, K., Nishioka, R. S., and Bern, H. A. (1980). Degranulation of the Stannius corpuscles of coho salmon (Oncorhynchus. kisutch) in response to ionic changes in vitro. Gen. Comp. Endocrinol. 41, 305-313.

Ball, J. N., and Ensor, D. M. (1967). Specific action of prolactin on plasma sodium levels in hypophysectomized Poecilia latipinna (Teleostei). Gen. Comp. Endocrinol. 8, 432-440.
Bern, H. A. (1975). Prolactin and osmoregulation. Amer. Zool. 15, 937-948.

Bliss, C. I. (1967), "Statistics in Biology," Vol. 1. McGraw-Hill, New York.

Bona-Gallo, A., and Licht, P. (1981). Gonadotropin specificity of in vitro testosterone secretion by fish testes. Gen. Comp. Endocrinol. 43, 467-478.

Burden, C. E. (1956). The failure of hypophysectomized Fundulus heteroclitus to survive in fresh water. Biol. Bull. 110, 8-28.

Clarke, W. C. (1973). Sodium-retaining bioassay of prolactin in the intact teleost Tilapia mossambica acclimated to sea water. Gen. Comp. Endocrinol. 21, 498-512.

Clarke, W. C. and Bern, H. A. (1980). Comparative endocrinology of prolactin. In "Hormonal Proteins and Peptides" (C. H. Li, Ed.). Vol. 8, pp. 105-197. Academic Press, New York.

Ensor, D. M., and Ball, J. N. (1968). A bioassay for fish prolactin (paralactin). Gen. Comp. Endocrinol. 11, 104-110.

Ensor, D. M., and Ball, J. N. (1972). Prolactin and osmoregulation in fishes. Fed. Proc. 31, 16151623.

Farmer, S. W., Papkoff, H., Bewley, T. A., Hayashida, T., Nishioka, R. S., Bern, H. A., and Li, C. H. (1977). Isolation and properties of teleost prolactin. Gen. Comp. Endocrinol. 31, 60-71.

Frye, B. E., Brown, P. S., and Snyder, B. W. (1972). Effects of prolactin and somatotropin on growth and metamorphosis of amphibians. Gen. Comp. Endocrinol. Suppl. 3, 209-220.

Grau, E. G., and Stetson, M. H. (1977). Pituitary autotransplants in Fundulus heteroclitus: Effect on thyroid function. Gen. Comp. Endoc,inol. 32, 427-431.

Idler, D. R., Shamsussaman, K. M., and Burton, M. P. (1978). Isolation of prolactin from salmon pituitary. Gen. Comp. Endocrinol. 35, 409-418.

Lahlou, B., and Giordan, A. (1970). Le contrôle hormonale des échanges et de la halance de l'ean chez le téléostéen d'eau douce Carassius auratus, intact et hypophysectomisée. Gen. Comp. Endocrinol. 14, 491-509.

Licht, P., and Crews, D. (1976). Gonadotropin stimulation of in vitro progesterone production in reptilian and amphibian ovaries. Gen. Comp. Endocrinol. 29, 141-151.

Loretz, C., and Bern, H. A. (1982). Prolactin and osmoregulation in vertebrates: An update. Neuroendocrinology 35, 292-304.

Muller, C. H. (1977). In vitro stimulation of $5 \alpha$-dihydrotestosterone and testosterone secretion from bulffrog testis by nonmammalian and mammalian gonadotropins. Gen. Comp. Endocrinol. 33, 109-121.

Muller, C. H., and Licht, P. (1980). Gonadotropin specificity of androgen secretion by amphibian testes. Gen. Comp. Endocrinol. 42, 365-377.

Pickford, G. E., Pang, P. K. T., and Sawyer, W. H. 
(1966). Prolactin and serum osmolality of hypophysectomized killifish, Fundulus heteroclitus, in freshwater. Nature (London) 209, 1040-1041.

Pickford, G. E., and Phillips, J. G. (1959). Prolactin, a factor in promoting survival of hypophysectomized killifish in freshwater. Science 130 , 454-455.

Pickford, G. E., Robertson, E. E., and Sawyer, W. H. (1965). Hypophysectomy, replacement therapy, and the tolerance of the euryhaline killifish, Fundulus heteroclitus to hypotonic media. Gen. Comp. Endocrinol. 5, 160-180.

Prunet, P., and Houdebine, L.-M. (1984). Purification and biological characterization of chinook saimon prolactin. Gen. Comp. Endocrinol. 53, 49-57.

Sage, M., and Bern, H. A. (1972). Assay of prolactir in vertebrate pituitaries by its dispersion of xanthophore pigment in the teleost Gillichithys mirabilis. J, Exp. Zool. 180, 169-174.

Sehdev, H. S., McBride, J. R., Fageriund, U: H.M. (1963). 2-Phenoxyethanol as a general anaesthetic for sockeye salmon. J. Fish. Res, Board Canada $20,1435-1440$.

Steel, R. G. D., and Torrie, J. H. (1960). "Principles and Procedures of Statistics." McGraw-Hill, New York. 